\title{
The potential of removing toxic elements from red sea water by using functionalised natural zeolite and synthetic zeolite
}

\author{
Mohammed ElTayeb Abd ElKarim and Dr. Saif Alnasr Abd Elmajed Said Ahmed
}

\author{
1.Ministry of Water Resources and Electricity Email: \\ aboeltayeba@yahoo.com \\ 2.University of Al-Neelain-Department of Chemistry Email: \\ Safco006@yahoo.com \\ ABSTRACT
}

\begin{abstract}
In this study five types of natural Zeolites and synthetic zeolites were used .Three types of synthetic zeolites (K-fledspar, clay and trona) were synthezied by using local crude materials by certain ratios, and the natural zeolite which used were collected from different states of Sudan , also the column that was used for treating hard water was prepared for natural zeolite, synthetic zeolite. The sample of red sea water was collected from Segala area at eastern side the of Port Sudan city, This area is the main source of Red sea water to the desalination plant, which supply the city with drinking water, study was investigated to determine the concentration of heavy metals, such as ( $\mathrm{Cu}, \mathrm{pb}, \mathrm{Fe}, \mathrm{Cd}, \mathrm{Zn}$ and $\mathrm{Co})$. The routine analysis was investigated to determine the other parameters of water.TDS concentration was determined by TDS meter. Concentration of heavy metals was measured by Atomic absorption. The synthetic zeolite and the natural zeolite which that were identified a long with XRD and IR. Also we were concentrated on remove the heavy metals from water during treatment process by synthetic zeolite and natural zeolite . Analysis results of elements in this study were analyzed, and the synthetic and natural zeolite were found to be better and Albite was found to be the best type in this study.
\end{abstract}

Key words: Zeolite, heavy metals, Albite, Infer Red, Total Dissolved Salts .

\section{INTRODUCTION}

Heavy metals can be toxic to living creature at certain levels. Although they occur naturally, they might also come from many different sources. These include some mining industries, burning of fossil fuels, like coal. (Allen et al. 1995, Sekar et al. 2004). Heavy metals are elements having atomic weights between63.5 and 200.6, and a specific gravity greater than 5.0. Living organisms require trace amounts of some heavy metals, including cobalt, copper, iron, manganese, molybdenum, vanadium, strontium, and zinc. (Alva et al., 1995). Heavy metals can enter human bodies via food, drinking water and air to a small extent. Although some heavy metals effects include reduced growth and development, cancer, organ damage, nervous system damage, are very important to maintain the metabolism of the human body as trace elements, they can lead to poisoning at higher concentrations. (Appel et al. 2002).

Heavy metals are among the normal constituents of the marine environmental but anthropogenic activities have contributed to th`e increase in metal contamination into marine environment and have directly influenced the coastal ecosystems (ELSikaily 2008). There are Considerable evidences in the scientific literature that contaminants such as trace metals can be taken up and concentrated by sediments and suspended matter in the Aquatic systems (Hart, 1982). The vertical and horizontal distributions of many trace elements in the ocean are determined by association with the cycle of growth, sinking and demineralization of marine phytoplankton. (Sommer et al., 2002; Al- Najjar, 2000). Metal pollution of the marine environment is less visible and direct than other types of marine pollution, but its effect on marine ecosystem and human are intensive and very extensive ( $P$ Grath 1990). Sediment contamination poses one of the worst environmental problems in marine ecosystem acting as sinks and source contaminations in aquatic systems. There is an evidence that in some coastal areas of the Mediterranean sea the input of eutrophying substances, particularly phosphorus .(Masoud 2005).

Zeolite is a Greek word that means "boiling stone," because naturally occurring zeolites are minerals that 
absorb water that subsequently boils when heated. Zeolites are microporous, crystalline aluminosilicates consisting of three components: framework tetrahedra, cations, and adsorbed molecules. Depending upon the framework and cations, the adsorbed phase feels a local electrostatic environment ranging from nonpolar to extremely polar (Nakhleh, B. V 1993, Duit, R.1991).

Natural microporous materials - zeolites occur in various geological environments and soil formations. Primary building units are ( $\mathrm{Al}, \mathrm{Si}) \mathrm{O} 4$ tetrahedra. When $\mathrm{Al} 3+$ substitutes $\mathrm{Si} 4+$ in the central cation position of the tetrahedron, a net-negative charge is generated and this charge is balanced by monovalent and divalent cations. Zeolites have an ability to exchange most of their constituent cations without major change of the structural framework( Pabalan, R. T2006, Collela, C., 2000 ).According to the IUPAC system [1], porous materials are classified according to their pore sizes into three classes: (i) Microporous, having pore sizes below $20 \AA$; (ii) Mesoporous, with intermediate pore sizes in the range 20 - $500 \AA$; and (iii) Macroporous, with pore sizes exceeding 500 Å. (K. S. W. 1985, M. E.1995). Zeolites are not phyllosilicates and for the most part they have crystal sizes above the $2 \mathrm{~mm}$ limit given as a definition of clay minerals. Water content $(\mathrm{H} 2 \mathrm{O})$ increases with increasing silica content. The structural relations crystalline space groups are very complicated in zeolite mineralogy, and in fact the same chemical composition can be expressed in two different, and co-existing, minerals.( Velde ,1995).

\section{MATERIALS and METHODS}

\section{Materials}

Sample Sources: Natural zeolites were collected from Doka Elglabat and Sahra Bayoda, the clays were collected from western Omdurman and the synthetic zeolite was prepared in Lab.

The water samples were collected from Red Sea from the shore of port Sudan City Segal area.
Prepration of Zeolite and Red kaoline: K-feldspar, clay and trona were added to red kaoline and crushed by mortar to apowder and the mixture was put in furnace 11000 for 6 hrs then stored in adescicator.

Preparation of natural zeolites: Natural zeolites were crushed to powder by mortar and the powder was washed by diionized water and puted in the oven for 2 hrs after that the powder was stored in adesicator.

Sample Processing: A Small column techniques was designed as a unit and the raw material of Zeolite was packed in the column and the water which contain hardness trace of heavy metals and other salts was passed through the column.

Test of Heavy metals: Flame AAS analysis was performed using a thermo Elemental Sollar M6 series atomic absorption spectrometer with air- acetylene flame. $\mathrm{Pb}, \mathrm{Zn}, \mathrm{Cd}, \mathrm{Cu}, \mathrm{Fe}$ and $\mathrm{Co}$ hollow cathode lamps were applied as sources. Standards of $\mathrm{Pb}, \mathrm{Zn}$, $\mathrm{Cd}, \mathrm{Cu}, \mathrm{Fe}$ ad Co were prepared from $1000 \mathrm{mg} / \mathrm{L}$ stock solutions- the aqueous solutions of $\mathrm{Pb}, \mathrm{Zn}, \mathrm{Cd}$, ions were analyezed after making the necessary dilution whenever required.

Analysis of solid phase FTIR: FTIR technique was applied to collect the spectra of the solid samples using a Niclet Magma 550 type instrument. The samples were introduced as pellets prepared from powders mixed with $\mathrm{KBr}$ and the spectra were recorded $\mathrm{KBr}$ powder pellets were used as a background.

XRD: The XRD analysis was performed using a Philips $X$ pert pro diffractometer, the sample were first ground, mounted on holders then introduced for analysis. Each sample was scanned with a step size identified by a search match procedure

(Keneth, 1990).

\section{RESULTS AND DISCUSSION:}

\section{All results were taken by ppm units}

Results of TDS and Heavy metals: The concentration of TDS and Heavy metals were shown in table 3.1 .below

\section{Methods:}


Table. 1 The result of TDS and Heavy metals

\begin{tabular}{|l|c|c|c|c|c|c|}
\hline Test & Raw & Z+Mg & Z+Red kaolin & Z+w kaolin & N.Z (1) & N.Z (2) \\
\hline TDS & 45430 & 21420 & 14900 & 27720 & 42840 & 30740 \\
\hline $\mathrm{Pb}$ & 0.818 & 0.0243 & 0.001 & 0.21 & 0.014 & 0.04 \\
\hline $\mathrm{Cu}$ & 0.630 & 0.0165 & $\mathrm{NiL}$ & 0.211 & 0.23 & 0.22 \\
\hline $\mathrm{Cd}$ & 0.262 & 0.0007 & $\mathrm{NiL}$ & 0.02 & 0.011 & 0.130 \\
\hline $\mathrm{Co}$ & 0.112 & 0.0104 & $\mathrm{NiL}$ & $\mathrm{NiL}$ & $\mathrm{NiL}$ & 0.042 \\
\hline $\mathrm{Zn}$ & 0.60 & 0.038 & $\mathrm{NiL}$ & 0.212 & 0.321 & $\mathrm{NiL}$ \\
\hline $\mathrm{Fe}$ & 3.92 & 0.0559 & 0.02 & 0.18 & 1.102 & 0.140 \\
\hline
\end{tabular}

The TDS of red sea water sample is about 42840 ppm wich is generally high within the range bettern 1000-15000 ppm due to high evaporation, low precipitation, and the lack of a major river inflow. Over all analysis of TDS, heavy metals, the best synthetic zeolite wich decrased the TDS, heavy metals is the zeolite and red kaoline which decreased the TDS from $42840 \mathrm{ppm}$ to $1444 \mathrm{ppm}$ and in this process we used $125 \mathrm{~g}$ of synthetic Zeolite to $1000 \mathrm{ml}$ of water sample. The exchange of multivalent metal ions can be achieved over $\mathrm{pH}$ range between 3-6.

The influence of TDS was very important in this study for efficient removal of heavy metals by ion exchange. In this study efficiency was low because of high TDS

The high value of TDS was due to increased of sodium ions and this increase of sodium ions was due to the ion exchange between water sample and zeolites. There fore its very difficult to remove this ions.

During the treatment process found that some ions can be removed and others like sodium was precipitated in water sample due to ion exchange, there fore these precipitated ions can increase the TDS level.

Over all results of heavy metals, showed that the average for samples before treatment was $1.223 \mathrm{ppm}$ and it was increased because of impurities in natural zeolites. Also, it is clear that the concentration is very high and the S.zeolites was removed these ions and the S.zeolties is better than natural zeolite in treatment. 
Am. J. Sci. Ind. Res., 2013, 4(3): 306-316

Figures of IR of Zeolites :

The figures of IR of Zeolites results were shown in figures from .1 to .3

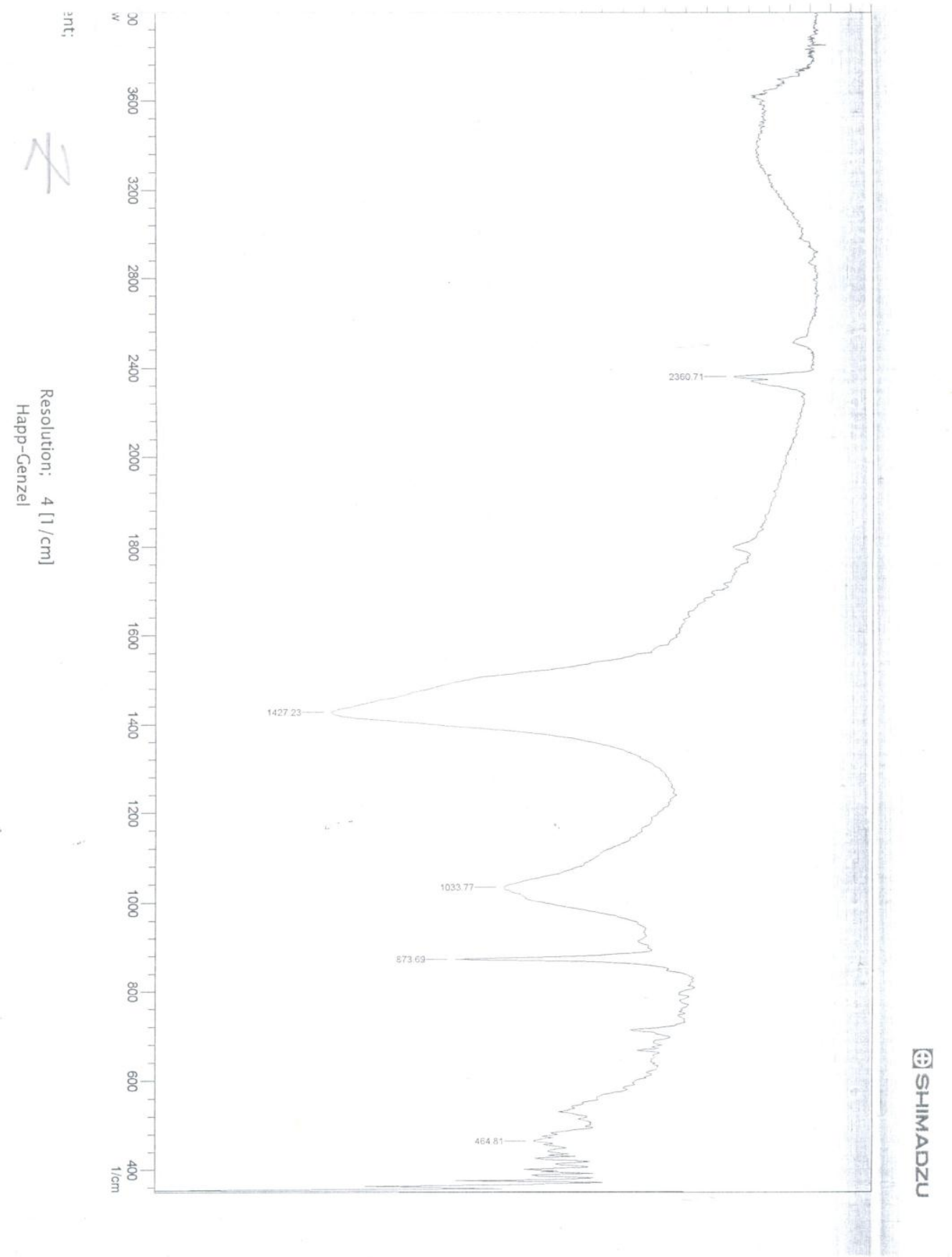

Fig .1 IR of N.Zeolite. 
Am. J. Sci. Ind. Res., 2013, 4(3): 306-316

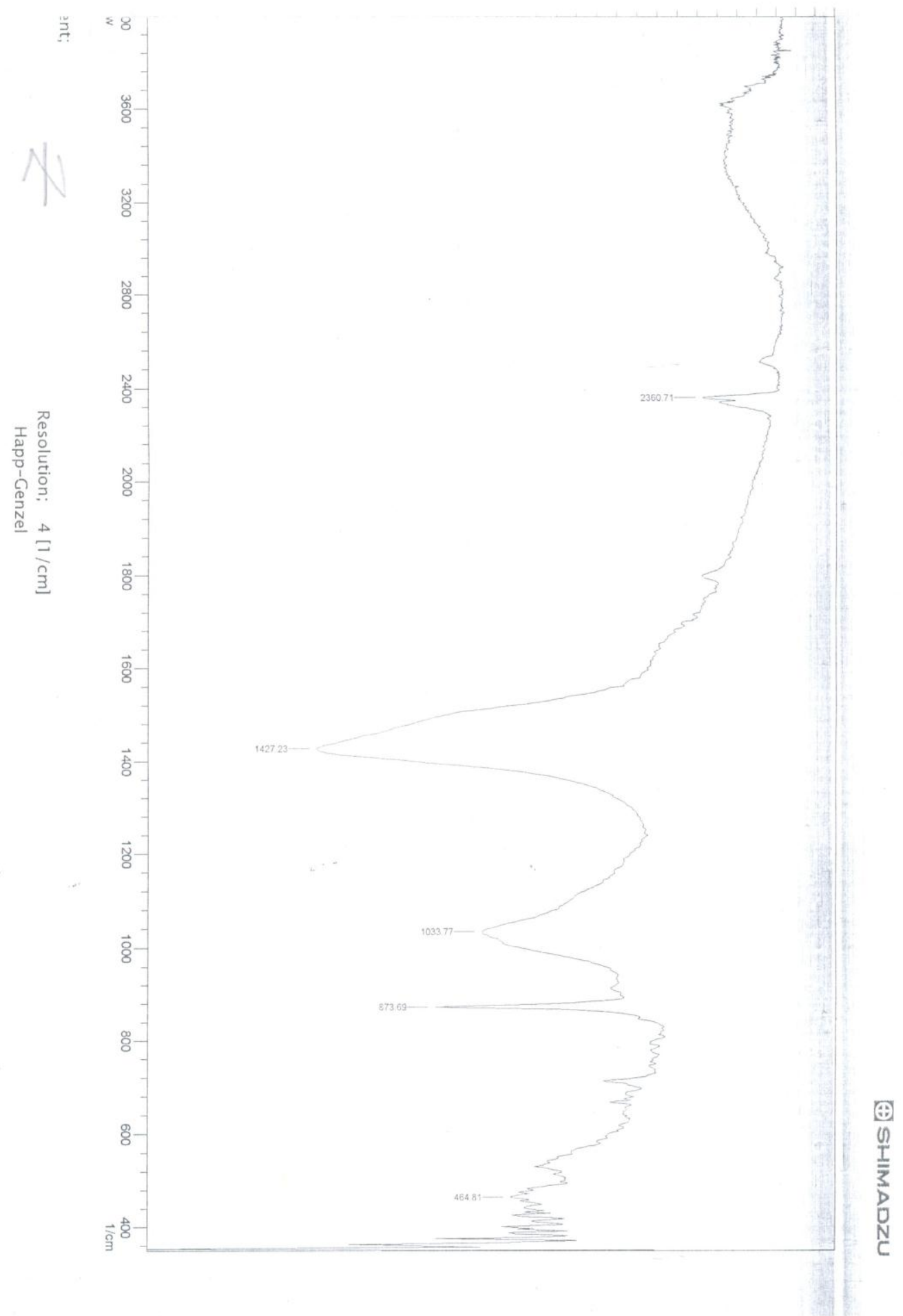

Fig .2 IR of S.Zeolite(4). 
Am. J. Sci. Ind. Res., 2013, 4(3): 306-316

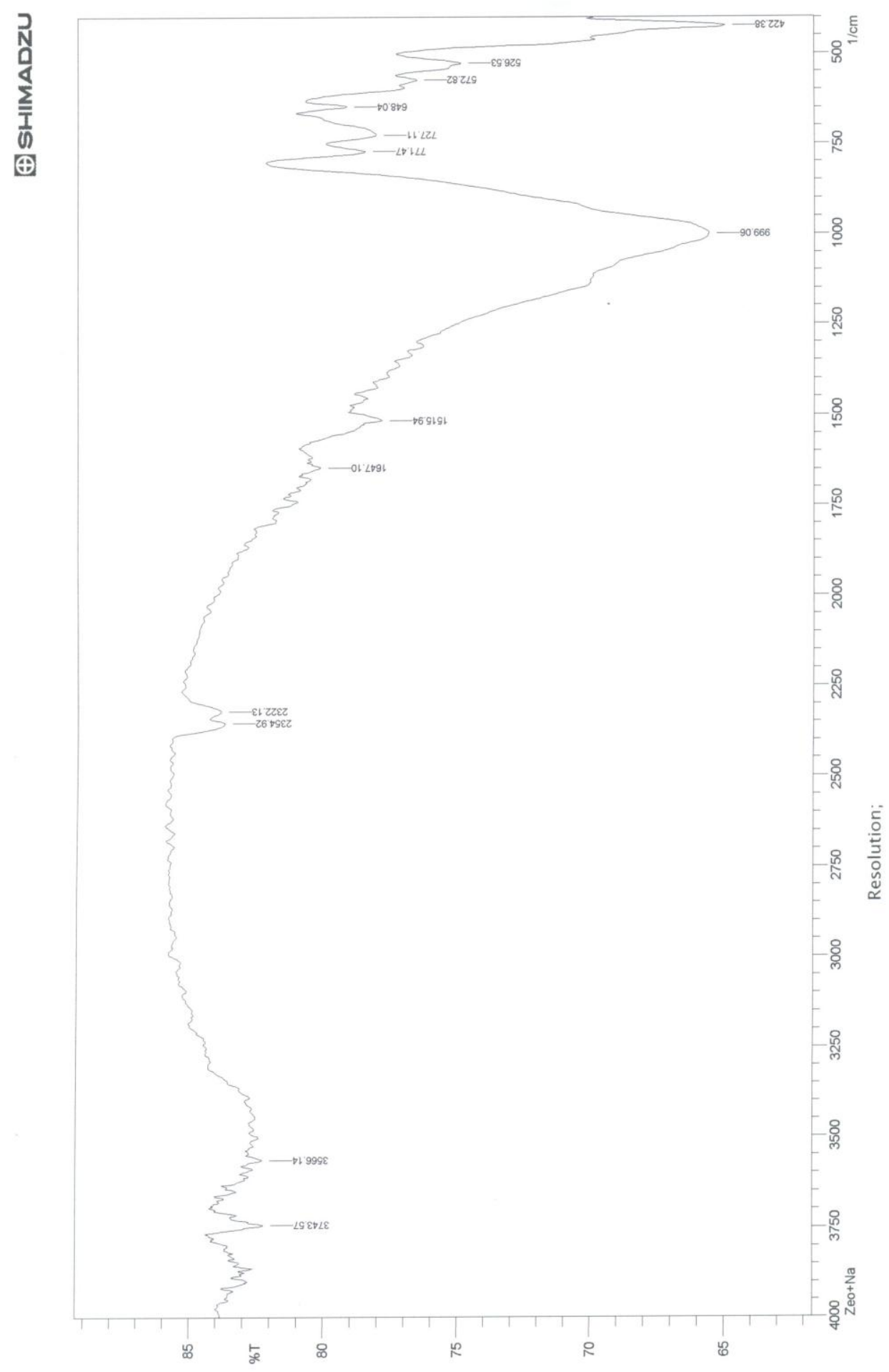

Fig .3 IR of S.Zeolite(5). 
Am. J. Sci. Ind. Res., 2013, 4(3): 306-316

Figures of XRD of Zeolites :

The results of XRD OF Zeolites were show in figures from .4_6

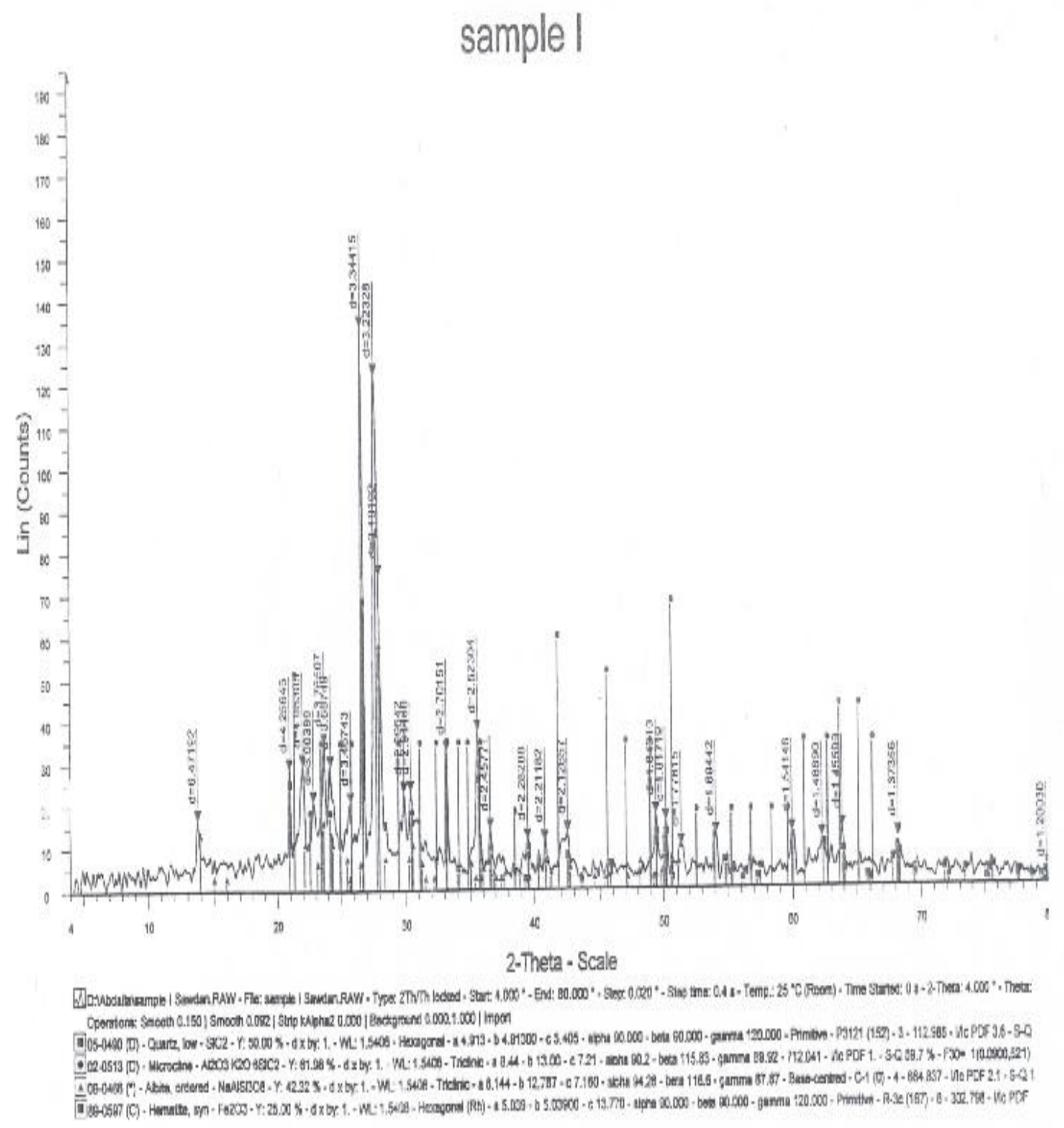

Fig .4 XRD of S.Zeolite (1). 
Am. J. Sci. Ind. Res., 2013, 4(3): 306-316

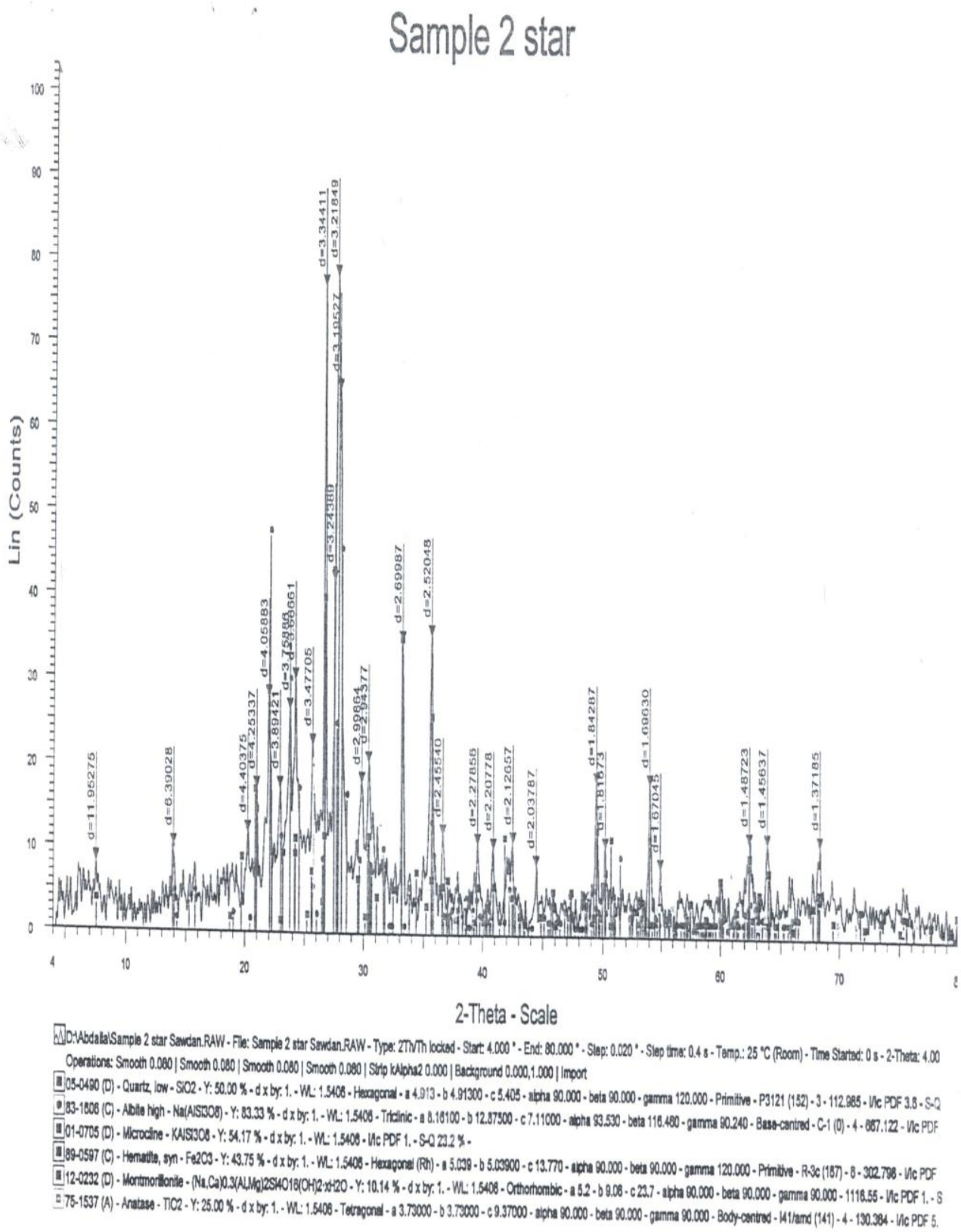

Fig .5 XRD of S.Zeolite (2). 
Am. J. Sci. Ind. Res., 2013, 4(3): 306-316

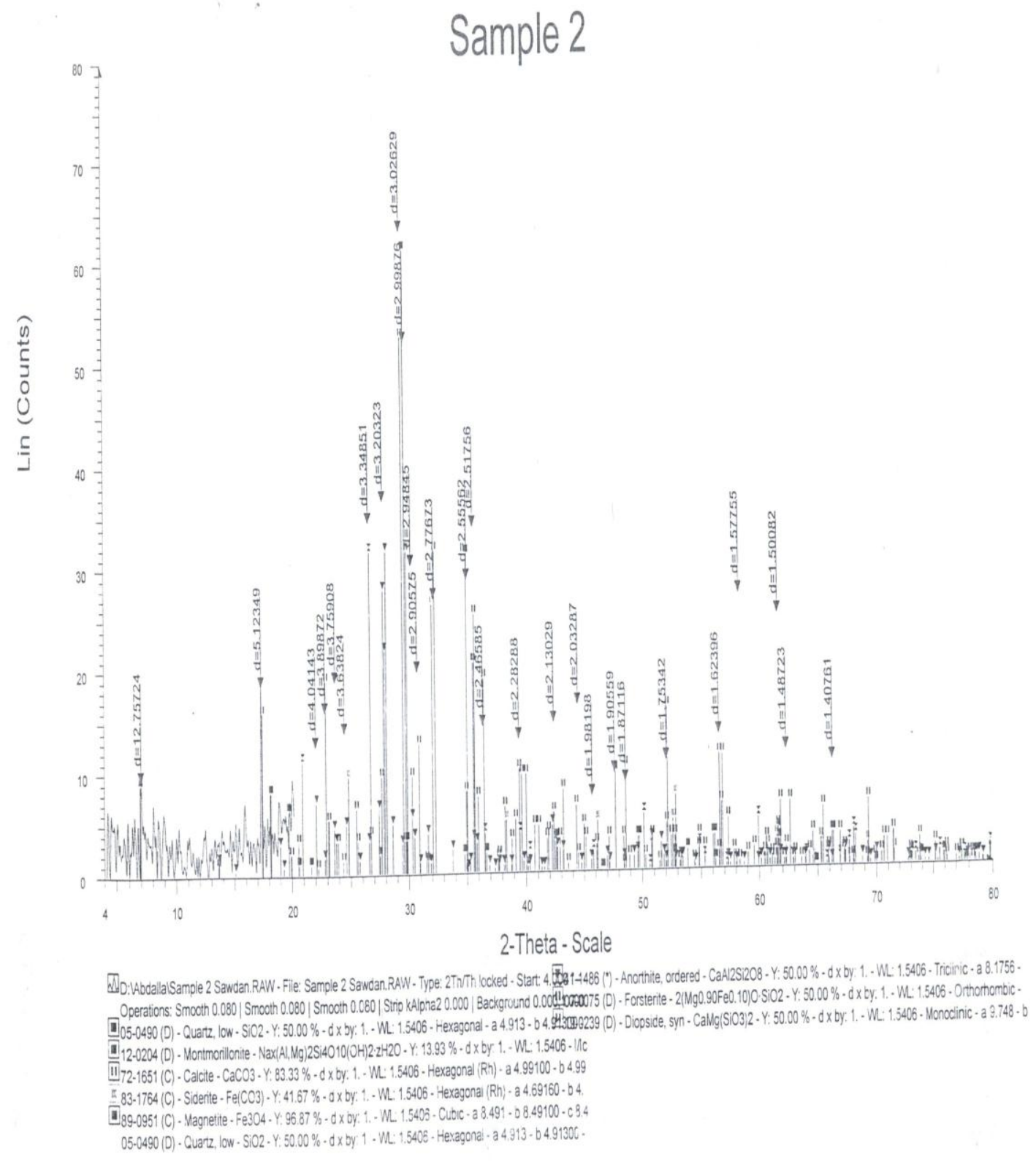

Fig .6 XRD of S.Zeolite (3) 


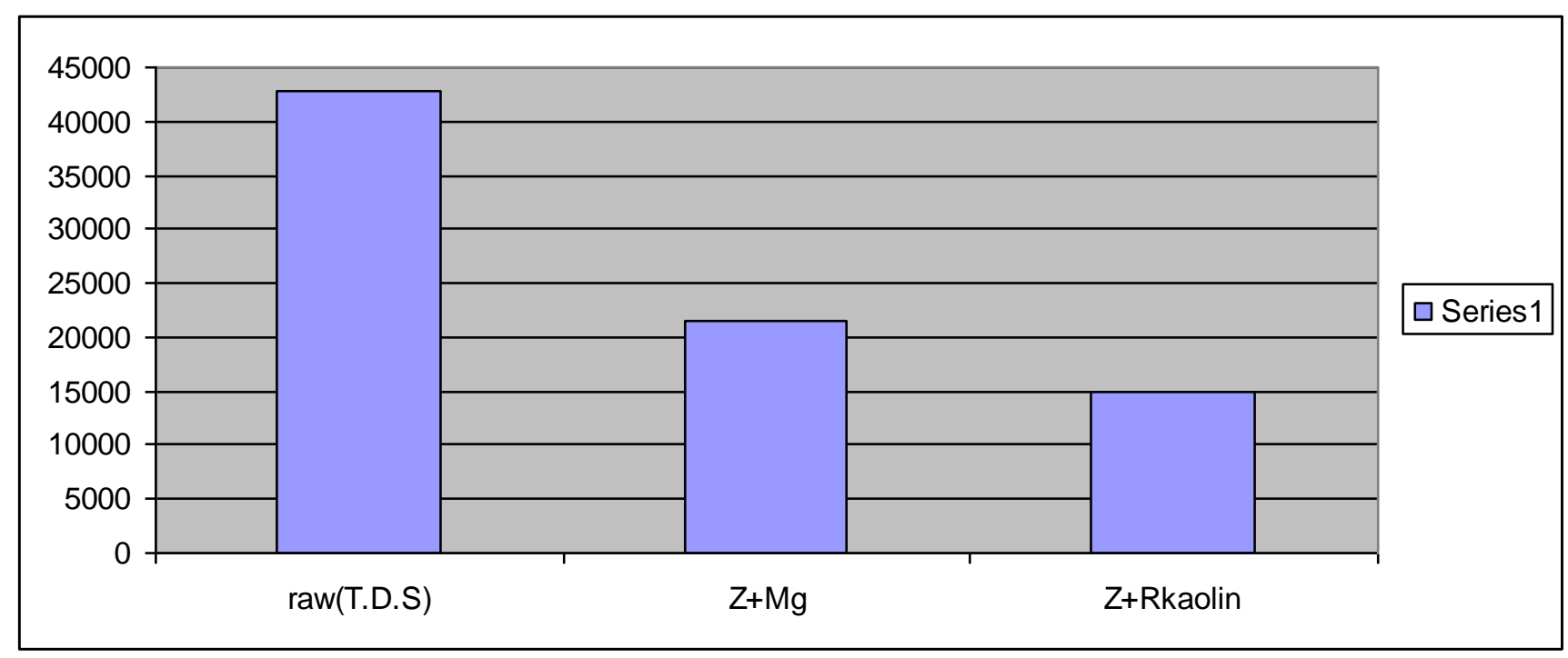

Fig .7 Comparison between Zeolite plus Red Kaoline and Zeolite plus Mg for removal of TDS.

S.zeolites is better than natural zeolite in treatment process although the weight of natural zeolites which was used in treatment process was double S.zeolite.

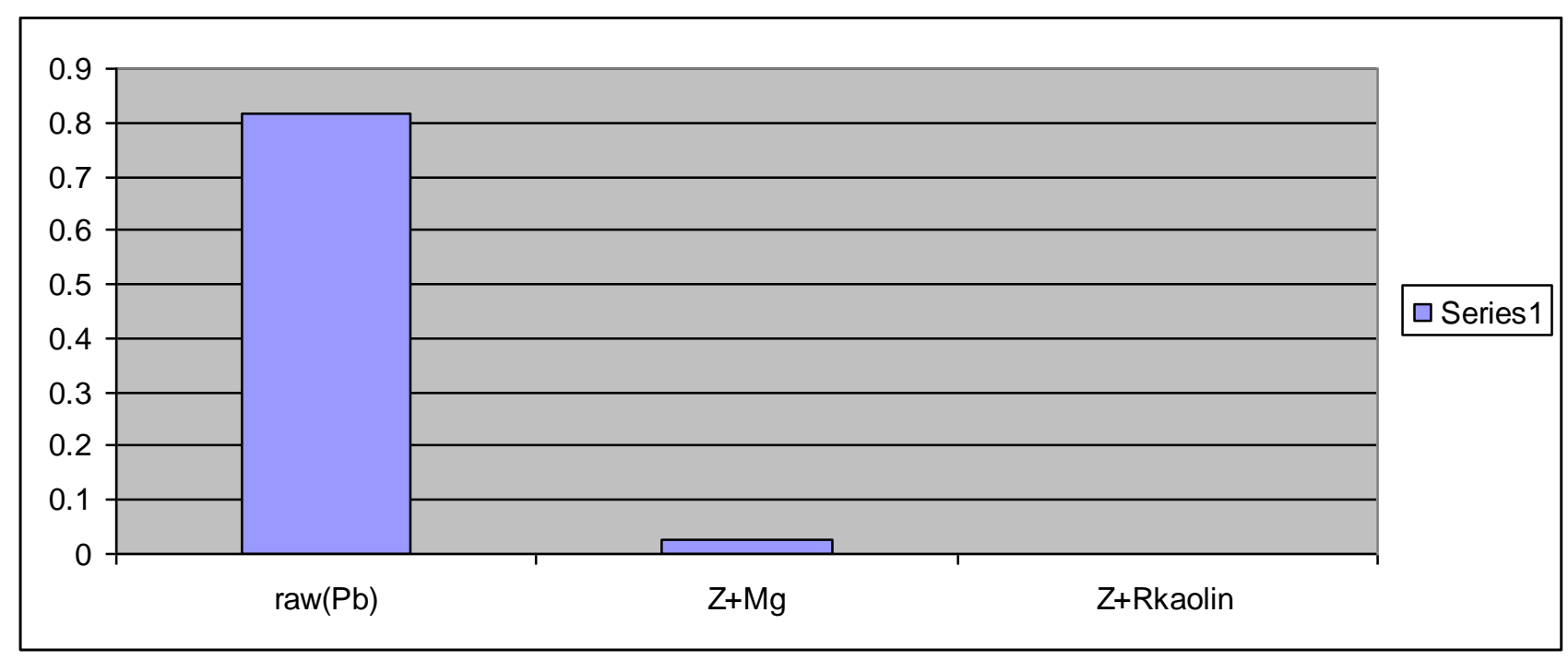

Fig .8 Comparison between Zeolite plus Red Kaoline and Zeolite plus Mg for removal of Lead 


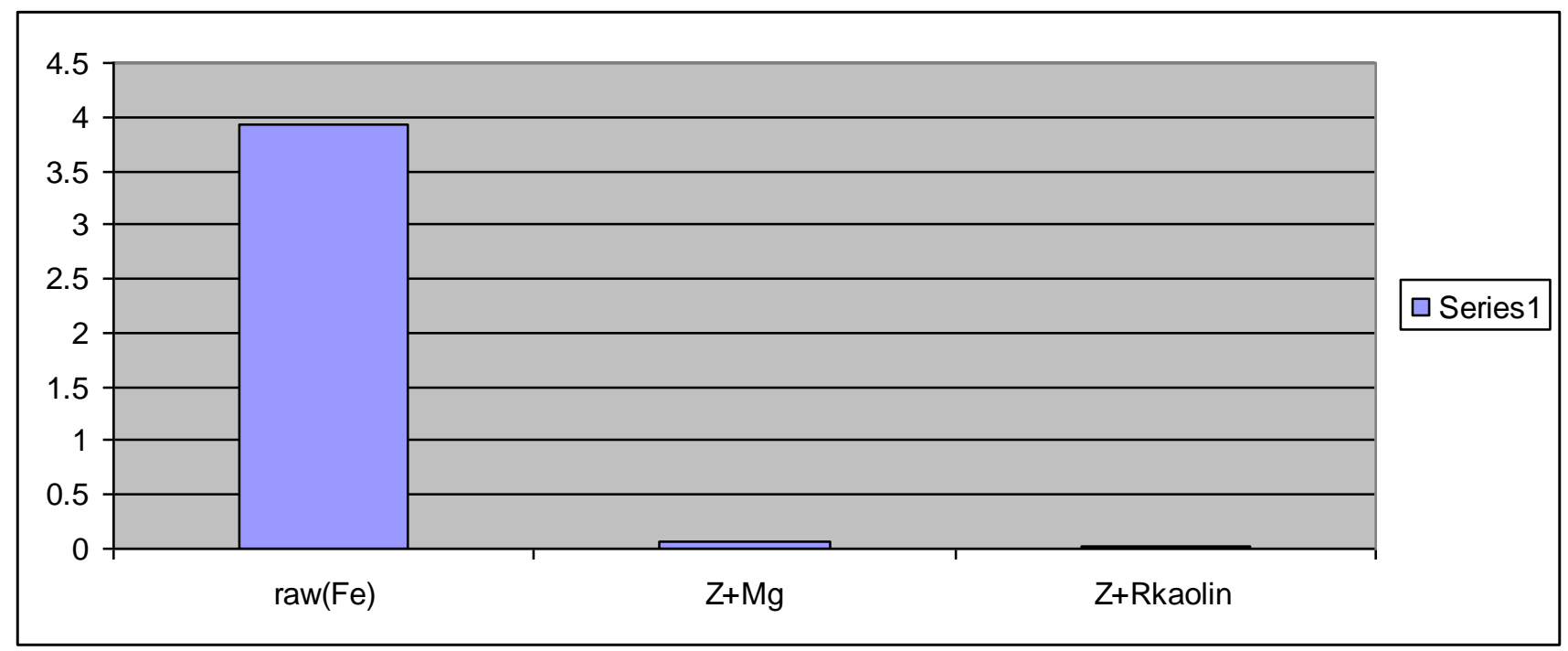

Fig .9 Comparison between Zeolite plus Red Kaoline and Zeolite plus Mg for removal of Iron

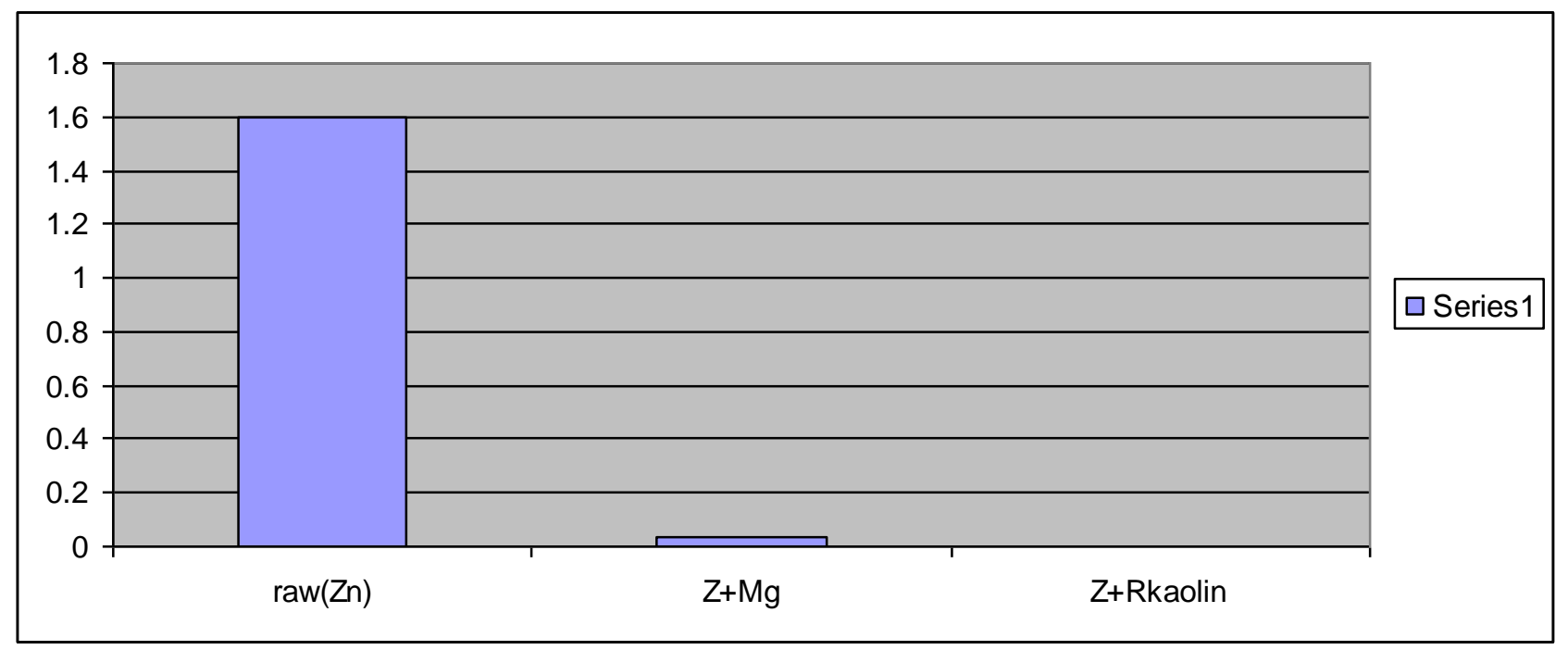

Fig .10 Comparison between Zeolite plus Red Kaoline and Zeolite plus Mg for removal of Zinc

\section{CONCLUSION}

Removal of heavy metals like (pb, $\mathrm{Zn}, \mathrm{Cu}, \mathrm{Cd}, \mathrm{Fe}$ and $\mathrm{Co}$ ) from red sea water was possible using natural zeolite, clay and synethetic zeolites which are prepared from (K-fledspar, clay, Trona, and trace element).

Found that synethetic zeolite was the best than clay and retrial zeolite.
Also that the type of zeolie Albite was the best to remove heavy metals .

In this study, sample magnesium ions were found to be the best ion exchange than calcium ions in sea water by synthetic zeolite compared to natural zeolite and clay (kaolinite and Bentonite).

Synthetic Zeoliite was synthied by natural substance and there was no contamination and pollution in the environment when synthetic zeolite was used. 
Finally, to be sure that the desalination of red sea water is the way to meet the demands of the shortage of the fresh water.

\section{REFRENCES}

Abdullah, A. M., , Hydrological structure and circulation of waters of the Red Sea (Russian), Moscow, University of $\operatorname{Moscow}(1985)$.

Allen, H.E., Huang, C.P., Bailey, G.W., Bowers, A.R., p.255. Metal Speciation and Contamination of Soil, ( Lewis Publishers, Florida,)( 1995).

Al-Najjar T. The seasonal dynamics and grazing control of phyto-and mesozooplankton in the northern Gulf of Aqaba (PhD- thesis), Germany: Bremen University(2000).

Alva Ak, Grahm JH, Anderson CA,59:481-487 Soil PH and copper effects on young 'Hamlin' orange trees. Soil Sci. Soc.Am. J. (1995).

Appel, C., Ma, L. Vol. 31, pp.581-589. "Concentration, pH, and surface charge effects on cadmium and lead sorption in three tropical soils", JEQ,( 2002).

Armbruster, T. \& Gunter, M. E., Vol. 45, pp. 1-68. Crystal structure of natural zeolites. In: Natural Zeolites: occurrence, properties; applications (eds Bish, D. L. \& Ming, D. W.) Reviews in Mineralogy \& Geochemistry,( 2001).

Barrer, R. M. Hydrothermal Chemistry of Zeolites. Academic Press, London(1982).

Bibudhendra Fiarkar, PP.22,29 . Heavy Metals in the Environment, The Hospital for Sick Children and University of Toronto Toronto, Ontario, Canada, (2002).

Brude Velde, PP.. 39,41. Orgin and Mineralogy of Clays. 24 rue Lhomond, Paris France,( 1995).

B; Schnack-Schiel; Astrid C; Wilhelm H; Stephen W; AlNajjar T; Anton FP. 2002. Grazing during the spring bloom in the Gulf of Aqaba and the Northern Red Sea.
Duit, R. 1991 In The Psychology of Learning Science; Glynn, S.; Yeany, R.; Britton,

EL-Sikaily, A.Mar. 50(9), 1197, Pollut. Bull, (2008).

Hart B. 91: 299-313. Uptake of trace metals by sediments and suspended particles: A review. Hydrobiologia, (1982).

Herlich.Kenneth., Official methods of analysis . 5th ed. Virginia USA(1990) .

K. S. W. Sing, D. H. Everett, R. H. W. Haul, L. Moscou, R. A. Pierotti, J. Rouquerol, T. Siemieniewska, Pure Appl. Chem. 57, 603, (1985) .

M. E. Davis, Ind. Eng. Chem. Res. 30, 1675 ,Gottardi, G., and E. Galli. Natural zeolites. Springer-Ver I ag, New York(1991).

Morcos, S. A., Ann. Rev. 8, pp. 73-202, 'Physical and chemical oceanography of the Red Sea', Oceanogr. Mar. Biol (1970).

M.S Masoud ,31,(2). R.B Nessim and N Maximous, Bull. Inst. Oceanogr. \& Fish, A.R.E (2005).

Nakhleh, B. V.; Mitchell, R. C. J. Chem. Educ. 70, 190 (1993)

Pabalan, R. T. : Discovering the properties of natural zeolite-ion exchange, 7th International conference on the occurence, properties and utilization of natural zeolite 06, Soccoro, New Mexico USA, Bowman $\mathrm{R}(2006)$.

P Grath wohl .24, 1687 Sci. Technol (1990).

Sommer U; Ulrike G; Berninger R; Böttger-Schnack; Thomas H; Herwig S; Sigrid 239:251-261 ,Marine Ecology Progress Series.

S., Delop S. E. (eds.), Collela, C., Mumpton, F. A. pp. 484: Naturalzeolites for the third Millenium, eds. De FredeEditore, Napoli, Italy (2000).

Yegorov, N. E., 3, pp. 34-56, 'Calculation of heat balance of the Red Sea' (Russian), J. Meteorology and Hydrology (1950). 